\title{
The Dark Side of Spectator Behavior: Effects of Spectator Dysfunctional Behavior on Anger, Rumination, and Revisit Intention
}

\author{
Kyungyeol Anthony Kim and Kevin K. Byon
}

Kyungyeol Anthony Kim, PhD, is a professor in the Department of Kinesiology at Indiana University of Bloomington. His research interests include exploring the psychological and environmental variables affecting consumer behavior within sport marketing and sport tourism.

Kevin K. Byon, PhD, is an associate professor in Department of Kinesiology at Indiana University. His research interests include psychological and environmental variables affecting consumer behavior within sport marketing and sport tourism.

\begin{abstract}
The purpose of this study is to examine the negative effects of spectator dysfunctional behavior (SDB) on other spectators' anger, rumination, and revisit intention. More specifically, in Study 1, we show that SDB (vs. spectator normal behavior [SNB]) elicited other spectators' anger and reduced revisit intention. Anger significantly mediated the relationship between SDB (vs. SNB) and revisit intention. The negative effects of SDB and anger on revisit intention became positive as team identification increased. In Study 2, we demonstrate that rumination regarding SDB incidents evoked focal spectators' anger and decreased revisit intention. Anger significantly mediated the relationship between rumination and revisit intention. Furthermore, the negative effects of rumination and anger on revisit intention were more significantly reduced in a high-level team identification group than in a low-level of team identification counterpart. Overall, the current work makes contributions to the sport management literature by shedding light on the dark side of sport spectatorship.
\end{abstract}

Keywords: spectator dysfunctional behavior, anger, rumination, team identification, revisit intention

DOI: http://doi.org/10.32731/SMQ.293.092020.06

\section{Introduction}

There was an incident that occurred on October 12, 2017 at the Bank of America Stadium during a National Football League (NFL) game between the Carolina Panthers and Philadelphia Eagles. A young man landed several punches on another spectator's face, casting a pall over observers' consumption experience. Unfortunately, this sort of horrifying if not shocking incident has become an increasingly common feature of spectator sport and continues to attract media attention, raising public and societal concerns (Spaaij, 2014). Spectator dysfunctional behavior (SDB) is defined as behavioral acts by spectators that "violate the generally accepted norms of conduct in consumption situations, and thus disrupt the consumption order" (Fullerton \&
Punj, 2004, p. 1239). Per the definition, it should be noted that any actions of SDB have to involve the violation of the generally accepted norms and thus the disruption of the consumption order. This is because spectators can engage in dysfunctional behavior in non-aggressive ways such as complaining (Wakefield \& Wann, 2006), which might neither violate the generally accepted norms nor disrupt the consumption order. Therefore, we operationalize SDB via spectator aggression, including verbal assaults and fighting (Wann \& James, 2019).

It is understood that any form of consumer dysfunctional behavior results in physical, psychological, and financial damages to organizations and employees. Note that SDB not only inflicts damage on victims but also negatively affects others' consumption experiences (Kim, Byon, \& Baek, 2019; Wann \& James, 2019), 
possibly decreasing their revisit intention (Hunt, Bristol, \& Bashaw, 1999). This is because social influence in consumption situations is not limited to direct interactions among spectators; rather, such influence can also occur in non-interactive ways, such as innocent bystanders becoming frustrated and upset when witnessing SDB (Kim, Byon, \& Baek, 2019). We define other spectators as those who "are in the service facility simultaneously with - and who are unacquainted with-a focal [spectator]" (Brocato, Voorhees, \& Baker, 2012, p. 385).

In the sport management literature, considerable attention has been devoted to understanding desirable factors (e.g., good service quality, sport spectatorship) predicting positive consumer behavior variables, such as behavioral intention (e.g., Jones, Byon, \& Huang, 2019) and life satisfaction (Inoue, Sato, Filo, Du, \& Funk, 2017). Less attention, however, has been given to understanding undesirable consumer behaviors (i.e., SDB) and their consequences with regard to other spectators and sport organizations. Although a number of researchers have attempted to investigate the phenomena of SDB, they have mainly focused on developing a profile of dysfunctional spectators and exploring the positive relationship between a high level of team identification (ID) and SDB. More specifically, Wann and James (2019) described personal and situational variables that contribute to the causes of SDB. Personal variables include team identification, dysfunctional fandom, and alcohol consumption. Situational variables include observational learning, poor performance, aggressive cues (e.g., a statement with aggressively titled rivalry games), environmental factors (e.g., noise), daily hassles, game opponents (e.g., rivals), deindividuation (e.g., feelings of anonymity), and cultural influences. Furthermore, prior scholars have reported that the a higher spectator's team ID is, the more likely they are to exhibit different forms of dysfunctional behaviors in various contexts, such as college basketball (Wann \& Goeke, 2018; Wann, Waddill, Bono, Scheuchner, \& Ruga, 2017), general spectator sport (Wann \& Ostrander, 2017), and youth baseball (Wann, Weaver, Belva, Ladd, \& Armstrong, 2015). The logic is that highly identified spectators who are obsessed with game outcomes tend to engage in SDB toward referees, players, and the opposing team's fans during a live sporting event (Spaaij, 2014; Wann \& James, 2019).

Although previous studies offer a starting point for scrutiny regarding SDB, what has yet to be addressed in the sport management literature pertains to other spectators' emotional, cognitive, and behavioral reactions to $\mathrm{SDB}$. To fill this gap, the purpose of the current study is to examine the negative effects of SDB on other spectators' anger, rumination, and revisit intention. Rumination is defined as "a passive and repetitive focus on the negative and damaging features of a stressful transaction" (Skinner, Edge, Altman, \& Sherwood, 2003, p. 242). In addition, we investigate the moderating effects of team ID on the relationship between anger and revisit intention as well as rumination and revisit intention. More specifically, via a series of pretests, we develop and validate experimental scenarios that describe SDB and spectator normal behavior (SNB) as a control condition and identify a negative emotion (i.e., anger) in the context of SDB. In Study 1, we examine (a) immediate effects of witnessing SDB (vs. SNB) on focal spectators' anger and revisit intention and (b) moderating effects of team ID between SDB (vs. SNB) and revisit intention and between anger and revisit intention. In Study 2, we extend Study 1 by examining the prolonged effects of SDB. We introduce the concept of rumination and empirically demonstrate that witnessing an SDB incident might be more than a one-off occurrence, prolonging focal spectators' memories after incidents. Furthermore, we test moderating influences of team ID between rumination and revisit intention and between anger and revisit intention.

\section{Theoretical Background}

\section{The Dark Side of Spectator Behavior}

Live sporting events provide opportunities for rich and intricate interactions among spectators (Kim, Byon, \& Baek, 2019; Kim, Byon, Baek, \& Williams, 2019). Given the social nature of spectatorship, other spectators are an integral part of individuals' consumption experiences and have the potential to significantly impact their service perceptions (Brocato et al., 2012). Spectator behaviors can be a double-edged sword, however, such that spectators' exhibitions of positive behaviors (e.g., cheering) can enhance focal spectators' excitement (Kim, Byon, Baek, \& Williams, 2019) while, as the opening account demonstrates, negative behaviors (e.g., cursing, even violence) undoubtedly diminish others' consumption experiences (Kim, Byon, \& Baek, 2019). SDB ranges from verbal assaults, fighting, invading playing arenas, and throwing missiles (e.g., bottles) to vandalism and terrorism (Spaaij, 2014; Wann \& James, 2019). Even when focal spectators are neither involved nor attempt to engage in SDB, their mere proximity to and observation of incidents can disrupt or ruin their consumption experiences (Miao, Mattila, \& Mount, 2011). By recognizing the need to control SDB during sporting events, Wakefield and Sloan (1995) included fan control as one of the stadium elements.

\section{The Relationships among SDB, Anger, and Revisit Intention: The Expectancy Violations Theory} The expectancy violations theory (Burgoon \& Hale, 1988) posits that individuals have expectations 
regarding others' behaviors, which serve to frame their perceptions of interactions, social information processes, and subsequent behaviors. As expectancies are based on social norms of typical and acceptable behaviors, when other individuals behave in ways that conform to expected patterns, a positive violation is likely to occur (Burgoon \& Hale, 1988). However, when others' behaviors are perceived as falling short of socially accepted expectations (e.g., SDB), a negative violation occurs, consequently resulting in unfavorable interaction outcomes (Bachman \& Guerrero, 2006; Burgoon \& Hale, 1988). What follows is that focal individuals seek to interpret and evaluate the violation to better understand transgressors, their improper behaviors, and how to further behave (Bachman \& Guerrero, 2006). The magnitude of discrepancies matters such that the greater the deviation from expectancy, the greater the negative consequences will be (Burgoon \& Hale, 1988).

Similarly, SDB, which exceeds the socially accepted variability, is likely to ruin others' consumption experiences (Fullerton \& Punj, 2004; Kim, Byon, \& Baek, 2019). More specifically, other consumer dysfunctional behavior is likely to evoke negative emotions including anger (Miao et al., 2011; Kim, Byon, \& Baek, 2019) and impinge on behavioral intention (Hunt et al., 1999). In line with the notion that emotions are in the central sphere of consumers' behavioral actions (Richins, 1997), a number of empirical studies have documented the positive effect of anger on retaliatory behavior (Bonifield \& Cole, 2007; Grégoire \& Fisher, 2008) and negative influences of anger on repurchase (Kalamas, Laroche, \& Makdessian, 2008) and word-of-mouth intention (Kalamas et al., 2008). Taken all together, the following hypothesis was proposed:

H1: Anger mediates the relationship between SDB (vs. SNB) and revisit intention.

\section{The Relationships among Rumination, Anger, and Revisit Intention}

Rumination refers to repetitive and past-oriented thoughts on negative content (Skinner et al., 2003). Such ruminative thoughts serve as a mechanism through which negative emotions might linger and persist rather than being transient and short-lived (Wang et al., 2013). Rumination, which is considered an involuntary occurrence in individuals' minds, reactivates and heightens transgression-related thoughts, exacerbating the current mood and reenergizing revenge-seeking behavior (McCullough, Bono, \& Root, 2007). The adverse effects of rumination of an incident might be extended to consumers' negative generalizations about an organization. For instance, Porath, MacInnis, and Folkes (2010) found that consumers who engaged in rumination on employee-employee incivility made negative generalizations about other employees and the organization.

Nolen-Hoeksema (1991) provided three explanations regarding the deleterious effects of rumination. First, rumination works as a vicious cycle. That is, the more an individual broods over bad memories, the more association with the incidents takes place, which in turn makes the individual depressed again. Second, people who ruminate in response to anger-evoking events might not engage in activities that provide positive reinforcement. This is because rumination hinders people from escaping their repetitive bad moods, even if they previously enjoyed the activities. Finally, rumination reduces individuals' problem-solving abilities because rumination interferes with the engagement of positive behavior, which causes individuals to become more pessimistic and depressed. Likewise, rumination regarding transgressions yields counterproductive effects by transferring at-that-time negative emotions into current emotional states or even amplifying the bad mood (McCullough et al., 2007).

Previous scholars state that rumination on upsetting incidents makes people feel more angry (e.g., McCullough et al., 2007; Porath et al., 2010) such that rumination on negative events maintains or worsens the angry feeling experienced (Baranik et al., 2017; Wang et al., 2013). Rusting and Nolen-Hoeksema (1998) reported that rumination exacerbates individuals' current states of anger, as "the content of angry ruminations is likely to fuel the mood" (p. 791). Rumination also influences consumers' behavioral intention such that rumination regarding negative experiences is likely to stimulate the desire to take revenge by engaging in negative word-of-mouth and behavioral intention (Strizhakova, Tsarenko, \& Ruth, 2012). More recently, Baranik et al. (2017) found that service employees' rumination regarding their consumers' mistreatment was negatively associated with job performance. McCullough et al. (2007) confirmed the mediating effect of anger between rumination and forgiveness intention such that individuals' rumination about transgressions leads to anger, which in turn decreases their forgiveness intention.

H2: Anger mediates the relationship between rumination and revisit intention.

\section{The Moderating Roles of Team ID}

As dominant theoretical lenses, identity theory (Burke, 1991) and social identity theory (Tajfel, 1981) have been used to examine team identification in the sport management literature (Jacobson, 2003; Lock \& Heere, 2017). Identity is defined as "a set of meanings applied to the self in a social role or situation defining what it 
means to be who one is" (Burke, 1991, p. 837). Identity theory has its basis in role-identity theory, which indicates that individuals' actions are formed by how they want to perceive themselves and to be perceived by others (Jacobson, 2003). People have role identities that represent their social roles (e.g., being a fan), which are directed by past behaviors and direct future behaviors (Trail, Anderson, \& Lee, 2017). Social identity theory, on the other hand, refers to "part of an individual's self-concept which derives from his/her knowledge of his/her membership of a social group (or groups) together with the value and emotional significance attached to that member" (Tajfel, 1981, p. 255). Unlike identity theory, which emphasizes role behaviors, social identity theory is focused on group membership based on individuals' self-perception and self-categorization (Jacobson, 2003; Lock \& Heere, 2017). In the context of the current study, our focus is on individuals' beliefs regarding the important role of being a sport fan of a certain team (Trail et al., 2017) rather than establishing and maintaining their ties to a social group. Therefore, by following Trail et al. (2017), we use identity theory to understand team identification and measure it accordingly.

Several researchers have shown that team ID can mitigate the negative influences on behavioral intention. For example, unlike low identified spectators, highly identified counterparts were not easily deterred by low quality sportscape elements (e.g., parking lots) when deciding whether to continue to attend games (Wakefield \& Sloan, 1995). More recently, Chien, Kelly, and Weeks (2016) examined the differing effects of sport scandals based on spectators' team ID levels. The authors found that highly identified spectators were more lenient with regard to their teams' transgressions than their low identified counterparts such that spectators with high team ID maintained positive attitudes toward their teams regardless of scandals. Yim and Byon (2018) also reported that highly identified spectators were less influenced by a poorly played game than low identified spectators with regard to revisiting the game.

At the heart of the literature review is that spectators with high team ID are better able to cope with bad situations (e.g., losing, scandals) in attending their favorite teams' games. Therefore, we predict team ID positively moderates the negative relationships between SDB (vs. $\mathrm{SNB}$ ) and revisit intention, between anger and revisit intention, and between rumination and revisit intention.

H3a: The negative effect of SDB (vs. SNB) on revisit intention becomes positive as team ID increases.

H3b: The negative effect of anger on revisit intention becomes positive as team ID increases.
H3c: The negative effect of rumination on revisit intention becomes positive as team ID increases.

\section{Overview of Studies}

Prior to testing the hypotheses through two main studies, a series of pretests were conducted. The purposes of the pretests were to (a) develop and validate survey experimental scenarios and (b) identify a negative emotion in the context of SDB. With the developed scenarios, Study 1 was conducted to examine Hypotheses 1, 3a, and 3b, followed by Study 2 in which we tested Hypotheses 2, 3b, and 3c.

\section{Pretests: Survey Experimental Scenarios and Identification of Negative Emotion}

Research Context. The NFL was chosen as a research setting because SDB incidents, ranging from jousting to death, take place most commonly in that professional sport context (Babb \& Rich, 2016). According to Babb and Rich (2016), who examined police data from all 32 NFL teams between 2011 and 2015, more than six spectators were arrested per game on average in each regular season. The situation stands in stark contrast to the English Premier League (EPL), which has seen a steady decline in the number of the spectator arrests. According to the BBC Sport (2018), the arrest rates in the EPL have fallen since the 2000-2001 season (e.g., 3,972 arrests in 2000-2001, 2,456 arrests in 2012-2013, 1,542 arrests in 2017-2018). Thus, the NFL setting was expected to allow participants to be more likely to associate themselves with SDB incidents.

Pretest 1: Identifying SDB Incidents. As there are different types of dysfunctional behaviors (Wann \& James, 2019), the purpose of Pretest 1 was to identify types of SDB incidents that commonly took place in the NFL game setting. Participants who had witnessed SDB during NFL games in the 2017-2018 regular season were recruited via Amazon's Mechanical Turk (MTurk) and were asked to provide accounts of their actual episodes. Prior to the survey, we used a screening question to ask whether potential participants had seen SDB incidents during NFL games. Participants were provided with the definition of SDB, which emphasized the fact that SDB had to involve a violation of generally accepted norms (Fullerton \& Punj, 2004). This criterion regarding SDB was important, as it helped to exclude subjective experiences of SDB. For instance, others' standing up in front of a focal spectator during an event and thus obstructing their view may be considered SDB for the victimized spectator. However, this might not be the case for others who consider this as a natural incident in spectator sport. A total of 61 participants $(60.4 \%$ male; average age $=33.4)$ who passed the screening question were asked to describe and specify 
their experiences of witnessing SDB incidents. After collecting the data, we listed the first two incidents that were mentioned the most and at least 10 times. Physical fighting (25 times) and drunken spectators yelling obscenities (17 times) were chosen.

Pretest 2: Selecting an SDB Incident. We further identified the most severe incident between the two listed in Pretest 1. A total of 65 NFL fans (62.1\% male; average age $=30.1$ ) were recruited through MTurk. Participants were randomly assigned to one of the two incident conditions (i.e., spectators' physically fighting and drunken spectators yelling obscenities during NFL games) and were asked to imagine themselves in the situation as instructed below:

Please read the following scenario carefully and imagine that the incident happened to you during an NFL game. Then answer the following questions. The success of this survey depends on whether you are really able to picture yourself in such a situation at a stadium.

Next, participants were asked to respond to three items of the severity of incidents adapted from Grégoire and Fisher (2008) using a seven-point Likert scale $(1=$ strongly disagree to $7=$ strongly agree). The items include (an incident) caused me problems, (an incident) caused me inconvenience, and (an incident) caused me aggravation. The results showed that the spectators' physical fighting was found to be of higher severity $(M=6.01 ; S D=.91)$ than that of drunken spectators yelling obscenities $(M=5.31 ; S D=1.10)$. Therefore, we chose the incident of spectators' physical fighting as SDB.

Pretest 3: Scenario Development. Following the identification of the SDB incident, we carefully developed scenarios by adapting them from Miao et al.s (2011) research. Two scenario conditions-treatment (i.e., SDB) and control (i.e., SNB) - in a restaurant setting were modified to fit the current study context. More specifically, an SDB condition describes other spectators engaging in physical fighting during an NFL game. An SNB condition, on the other hand, depicts other spectators engaging in normal behavior (see Appendix A).

We tested the realism of the developed scenarios to ensure that participants had no problem imagining themselves in the two conditions. Participants consisting of 86 NFL fans $(66.1 \%$ male; average age $=30.1)$ took part in this survey experiment via MTurk. They were randomly assigned to one of the two conditions ( $n=43$ for SDB; $n=43$ for SNB) and then asked to respond to two realism items regarding how realistic the situation was and how easy it was to imagine themselves in the situation. A seven-point Likert scale
( $1=$ strongly disagree to $7=$ strongly agree $)$ was used. The results indicated that the mean values for both conditions of SDB $(M=6.12 ; S D=.88)$ and SNB $(M=$ 6.09 ; $S D=.95)$ were high, ensuring the realism of the two scenarios.

Pretest 4: Identifying a Negative Emotion. Although previous researchers used global measures of emotions (i.e., positive vs. negative) in spectator sport (e.g., Yim \& Byon, 2018), different types of emotions can be elicited via different contexts (Manstead \& Fischer, 2001). Dichotomous measures of emotions might not reflect variations of specific emotional reactions arising from appraisals of unique situations (Manstead \& Fischer, 2001). In the present study, we focus on anger as a negative emotion elicited by SDB for three reasons.

First, in previous studies, anger has been treated as the most dominant emotional reaction as a consequence of service failure (e.g., Bonifield \& Cole, 2007; Kalamas et al., 2008). When the service offered fails to fulfill consumers' needs due to, for example, $\mathrm{SDB}$, anger is likely to be the emotion consumers first experience (Bonifield \& Cole, 2007). Second, anger, unlike other negative emotions (e.g., sadness), requires attributable agents to be held accountable and blamable (Lazarus, 1991). This suggests that witnessing SDB elicits anger because of the existence of blamable agents (Lazarus, 1991). Finally, by using the developed SDB scenario, we empirically demonstrate that anger is the most appropriate negative emotional reaction in the context of SDB. This test is expected to strengthen the aforementioned theoretical argument and provide researchers with empirical evidence that emotions are context-specific (Manstead \& Fischer, 2001). Through MTurk, 68 NFL fans $(64.7 \%$ male; average age $=34.4)$ participated in this survey experiment. Participants were instructed to read the SDB scenario and then asked to answer negative emotion items of anger, discontent, worry, sadness, fear, and shame based on a five-point Likert scale $(1=$ not at all to $5=$ a great deal) (Richins, 1997). The result showed that anger ( $M$ $=4.04 ; S D=.87)$ was evoked more frequently than discontent $(M=1.86 ; S D=1.03)$, worry $(M=2.70 ; S D=$ $1.05)$, sadness $(M=2.31 ; S D=1.08)$, fear $(M=1.86 ; S D$ $=1.10)$, and shame $(M=1.94 ; S D=1.10)$. The mean differences between anger and other emotions were all significant $(p<.001)$. The results suggested that anger be selected as the negative emotion in the SDB context.

Pretest 5: Manipulation Check. A manipulation check of the survey experimental scenarios was conducted. A total of 99 NFL fans (67.7\% male; average age $=33.3$ ) were surveyed through MTurk. Participants were randomly assigned to one of the two conditions 
Table 1. Descriptive Statistics and Reliability in Study 1

\begin{tabular}{|c|c|c|c|c|}
\hline & $\begin{array}{c}\text { SDB } \\
\text { (vs. SNB) }\end{array}$ & Anger & $\begin{array}{c}\text { Revisit } \\
\text { Intention }\end{array}$ & $\begin{array}{c}\text { Team } \\
\text { Identification }\end{array}$ \\
\hline $\mathrm{SDB}\left(\right.$ vs. SNB) ${ }^{\mathrm{a}}$ & - & & & \\
\hline Anger & $.72^{\star *}$ & .77 & & \\
\hline Revisit intention & $-.73^{\star *}$ & $-.69^{\star *}$ & .75 & \\
\hline Team identification & -.02 & -.08 & $.16^{*}$ & .62 \\
\hline Mean (standard deviation) & - & $2.36(1.33)$ & $4.69(1.05)$ & $6.09(.75)$ \\
\hline Composite reliability & - & .91 & .92 & .83 \\
\hline
\end{tabular}

( $n=50$ for SDB; $n=49$ for SNB) and asked to imagine themselves in the assigned situation. Upon reading the scenarios, participants responded to the items of the severity of incidents that were used in Pretest 2 . The result indicated that the severity of incident was higher in the SDB condition $(M=6.18 ; S D=.77)$ than in the SNB condition $(M=1.55 ; S D=1.20)(p<.001)$. Furthermore, participants responded to negative (i.e., anger) and positive (i.e., joy) emotion items. It was predicted that SDB would be more likely to elicit anger than SNB, and SNB would be more likely to evoke joy than SDB. Anger was measured with the same items used in Pretest 4, and joy was assessed with three items (i.e., happy, pleased, and joyful) from Richins (1997). The results showed that anger was higher in the SDB condition $(M=3.26 ; S D=.97)$ than in the SNB condition $(M=$ $1.59 ; S D=.93)(p<.001)$. Joy was higher in the SNB group $(M=3.24 ; S D=1.01)$ than in the SDB group $(M$ $=1.68 ; S D=.94)(p<.001)$. These results confirmed the successful manipulation of the scenarios. ${ }^{1}$

\section{Study 1}

\section{Method}

Participants and procedure. A single-factor (spectator behaviors; SDB vs. SNB) between-subject design was used in which 180 NFL fans (67.8\% male; average age $=36.8$ ) were recruited through MTurk. Participants were randomly assigned to one of the two conditions ( $n=93$ for SDB; $n=87$ for SNB). Participants were

1 To prevent the inclusion of any duplicate participants across the pretests, a screening question was created in all studies in which participants were required to provide their MTurk worker IDs. Then, their IDs were added to Qualtrics after completion of each test. Qualtrics allowed us to exclude potential respondents who had previously participated in the surveys by matching their IDs before taking part in a survey. Thus, duplicate answers were properly precluded. first exposed to an introductory statement and asked to imagine themselves in the one of the two situations. Next, they were asked to respond to questions of a manipulation check (the severity of incidents), anger (mediator), revisit intention (dependent variable), team ID (moderator), and demographics.

Measures. The same items of the severity of incidents (Pretests 2 and 5) and anger (Pretests 4 and 5) were used for Study 1. Three items from Trail and James's (2001) team identification index (TII) were used with a seven-point Likert scale $(1=$ strongly disagree to $7=$ strongly agree). The scale of TII is appropriate in the present study as it captures the extent to which one's role of being a fan is important (Trail et al., 2017). Revisit intention was assessed with four items adapted from Song et al. (2014) with a seven-point Likert scale $(1=$ strongly disagree to $7=$ strongly agree) (see Appendix B for all items).

Results. Table 1 shows descriptive statistics and correlations. The result of confirmatory factor analysis (CFA) indicated an acceptable model fit to data $\left(\chi^{2}=\right.$ 160.87, $d f=32, p<.05, \mathrm{CFI}=.91$, and TLI $=.95)($ Hoyle \& Panter, 1995). All composite reliability (CR) (>. 70) and average variance extracted (AVE) $(>.50)$ values were greater than suggested cutoffs (Fornell \& Larcker, 1981) (see Table 1). All AVE values were higher than the squared correlations of pairs of constructs, ensuring discriminant validity (Fornell \& Larcker, 1981).

The manipulation check was successful, as participants in the SDB group $(M=6.34 ; S D=.78)$ reported a greater severity of incidents than those in the SNB group $(M=1.80 ; S D=1.26)(p<.001)$. Hayes's $(2013)$ PROCESS macro was used to test the hypotheses. The results showed that SDB (vs. SNB) positively predicted anger $(B=2.19, p<.001)$ and negatively affected revisit intention $(B=-4.69, p<.05)$. Anger was negatively associated with revisit intention $(B=-1.85, p<.01)$. A 
Table 2. The Results Direct, Moderating, and Mediating Effects in

\begin{tabular}{|c|c|c|c|c|}
\hline \multirow[b]{2}{*}{ Relationships } & \multirow[b]{2}{*}{ B } & \multirow[b]{2}{*}{ SE } & \multicolumn{2}{|c|}{$\begin{array}{c}\text { Bias-Corrected } \\
95 \% \text { CI }\end{array}$} \\
\hline & & & Lower & Upper \\
\hline \multicolumn{5}{|l|}{ Predictor on anger } \\
\hline SDB (vs. SNB) & $2.19^{* * *}$ & .11 & 1.97 & 2.41 \\
\hline \multicolumn{5}{|l|}{ Predictors on revisit intention } \\
\hline SDB (vs. SNB) & $-4.69^{*}$ & .81 & -1.12 & -.25 \\
\hline Anger & $-1.85^{\star \star}$ & .70 & -3.22 & -.49 \\
\hline Team ID & $.96^{* * *}$ & .22 & .54 & 1.39 \\
\hline SDB (vs. SNB) x Team ID & $.44^{* * *}$ & .12 & .21 & .67 \\
\hline Anger x Team ID & $.66^{*}$ & .31 & .05 & 1.27 \\
\hline \multicolumn{5}{|l|}{ Mediating effect } \\
\hline SDB (vs. SNB) $\rightarrow$ Anger $\rightarrow$ Revisit intention & -1.22 & .34 & -1.90 & -.60 \\
\hline
\end{tabular}

Note: $\mathrm{SDB}=$ Spectator dysfunctional behavior; $\mathrm{SNB}=$ Spectator normal behavior. ${ }^{*} p<.05,{ }^{* *} p<.01,{ }^{* * *} p<.001$.

bias-corrected 95\% confidence interval (CI) was computed based on a bootstrapping technique with 5,000 samples to test the mediating effect. The result indicated that anger significantly mediated the relationship between SDB (vs. SNB) and revisit intention $(B=-1.22$, $\mathrm{CI}=-1.90$ to -.60 ), supporting Hypothesis 1 .

As for the moderating effects of team ID, the negative effect of SDB (vs. SNB) on revisit intention became positive as team ID increased $(B=.44, p<.001)$. Similarly, team ID positively moderated the negative relationship between anger and revisit intention $(B=$ $.66, p<.05)$. These results supported Hypotheses $3 \mathrm{a}$ and $3 \mathrm{~b}$ (see Table 2 for the direct, moderating, and mediating results).

Discussion. In support of Hypothesis 1, the results demonstrated that SDB (vs. SNB) evoked focal spectators' anger and consequently reduced revisit intention. We found the significant mediating effect of anger between SDB (vs. SNB) and revisit intention. In other words, merely witnessing an SDB incident without direct involvement might elicit focal spectators' anger, which in turn might decrease their revisit intention. Overall, Study 1 provided the preliminary evidence on the mechanism through which SDB might lessen other spectators' revisit intention via elicited anger. Furthermore, we found that team ID altered the negative effects of SDB and anger on revisit intention, such that spectators with high team ID reported their intention to revisit despite witnessing SDB and feeling angry.

However, limitations exist in Study 1. First, we examined the immediate effects of SDB on anger and revisit intention. It can be argued that spectators' negative experiences of witnessing SDB might go beyond the immediate consumption situation by causing ruminating effects after the event (Porath et al., 2010; Wang et al., 2013). More specifically, it is unclear whether witnessing SDB leads to rumination that in turn evokes anger and affects behavioral intention at a later time. To test this speculation, we introduce the concept of rumination in the following Study 2 and empirically examine how rumination on SDB elicits anger and impinges on revisit intention. We also investigate the boundary conditions under which negative influences of rumination might no longer remain or are weakened. We test the moderating effects of team ID in the negative relationship between rumination and revisit intention and between anger and revisit intention.

Second, in Study 1, we did not consider a low level of team ID group in the moderation analysis because the context in the scenarios was a participant's favorite NFL team's game. In Study 2, we use a random NFL game and test how different levels of team ID play different moderating roles. Via Study 2, we replicate Hypothesis $3 \mathrm{~b}$ and examine Hypotheses 2 and $3 c$.

\section{Study 2 \\ Method}

Participants and procedure. As rumination is characterized by repetitive thoughts on past experiences (Skinner et al., 2003; Wang et al., 2013), participants were asked to recall their actual experiences of witnessing SDB at NFL games. A screening question that asked whether participants had experience of seeing SDB during an NFL game was given. In accordance with Pretest 1, participants read the definition of SDB and were asked to answer the question based on the definition. A total of 195 participants (69.7\% male; average age $=32.5$ ) were recruited via MTurk. To 
Table 3. Descriptive Statistics and Reliability in Study 2

\begin{tabular}{lcccc}
\hline & Rumination & Anger & $\begin{array}{c}\text { Revisit } \\
\text { Intention }\end{array}$ & $\begin{array}{c}\text { Team } \\
\text { Identification }\end{array}$ \\
\hline Rumination & .71 & & & \\
Anger & $.67^{* *}$ & .65 & & \\
Revisit intention & $-.59^{* *}$ & $-.53^{* *}$ & .85 & .54 \\
Team identification & .04 & .03 & $.14^{*}$ & $5.22(.99)$ \\
\hline $\begin{array}{l}\text { Mean }(\text { standard deviation) } \\
\text { Composite reliability }\end{array}$ & $4.22(1.36)$ & $2.95(1.04)$ & $3.58(1.53)$ & .77 \\
\hline $\begin{array}{l}\text { Note: }{ }^{*} p<.05,{ }^{* *} p<.01, \text { two-tailed. The diagonal bold numbers represent average } \\
\text { variance extracted values. }\end{array}$ & .95 & & .84 &
\end{tabular}

facilitate recall process, participants were required to write down a brief but specific recollection of their experiences. Upon completing the recall task, participants responded to items assessing rumination (independent variable), anger (mediator), revisit intention (dependent variable), team ID (moderator), and demographics.

Measures. The measures of anger, revisit intention, and team ID were assessed with the same items used in the previous tests. Rumination was measured with eight items adapted from McCullough et al. (2007) using a seven-point Likert scale ( 1 = strongly disagree to $7=$ strongly agree) (see Appendix B for all items).

Results. Table 3 reports descriptive statistics and correlations. CFA revealed a good model fit to data $\left(\chi^{2}\right.$ $=247.81, d f=129, p<.05$, CFI $=.96$, TLI $=.95)($ Hoyle \& Panter, 1995). As shown in Table 3, CR (>. 70) and AVE (> .50) scores exceeded the cutoff values (Fornell \& Larcker, 1981). All AVE values exceeded the squared correlations of all pairs of constructs (Fornell \& Larcker, 1981).

The results of Hayes's (2013) PROCESS macro revealed that rumination positively predicted anger $(B$ $=.51, p<.001)$ and negatively affected revisit intention $(B=-1.65, p<.001)$. Anger negatively influenced revisit intention $(B=-2.65, p<.001)$. The bootstrapping result supported the significant mediating effect of anger between rumination and revisit intention $(B$ $=-.26, \mathrm{CI}=-.42$ to -.10$)$. Therefore, Hypothesis 2 was supported. The moderating effects of team ID were also significant, such that team ID positively moderated the negative relationships between rumination and revisit intention $(B=.28, p<.01)$ and between anger and revisit intention $(B=.51, p<.001)$ (see Table 4 for the results). Thus, Hypotheses $3 \mathrm{~b}$ and $3 \mathrm{c}$ were supported.

To look more closely at what levels of team ID groups were more or less influenced by rumination and anger in engaging in revisit intention, we further examined

Table 4. The Results Direct, Moderating, and Mediating Effects in

Study 2

\begin{tabular}{|c|c|c|c|c|}
\hline \multirow[b]{2}{*}{ Relationships } & \multirow[b]{2}{*}{ B } & \multirow[b]{2}{*}{ SE } & \multicolumn{2}{|c|}{$\begin{array}{c}\text { Bias-Corrected } \\
95 \% \mathrm{CI}\end{array}$} \\
\hline & & & Lower & Upper \\
\hline \multicolumn{5}{|l|}{ Predictor on anger } \\
\hline Rumination & $.51^{* * *}$ & .04 & .43 & .59 \\
\hline \multicolumn{5}{|l|}{ Predictors on revisit intention } \\
\hline Rumination & $-1.65^{\star * *}$ & .44 & -2.53 & -.78 \\
\hline Anger & $-2.65^{\star \star *}$ & .72 & -4.07 & -1.24 \\
\hline Team ID & .17 & .25 & -.34 & .67 \\
\hline Rumination $\mathrm{x}$ Team ID & $.28^{\star *}$ & .08 & .12 & .44 \\
\hline Anger x Team ID & $.51^{\star * *}$ & .13 & .25 & .78 \\
\hline \multicolumn{5}{|l|}{ Mediating effect } \\
\hline Rumination $\rightarrow$ Anger $\rightarrow$ Revisit intention & -.26 & .08 & -.42 & -.10 \\
\hline
\end{tabular}


Table 5. Conditional Direct Effects of Team ID in Study 2

\begin{tabular}{|c|c|c|c|c|}
\hline \multirow{2}{*}{$\begin{array}{l}\text { Team ID Between Anger } \\
\text { and Revisit Intention }\end{array}$} & \multirow[b]{2}{*}{ B } & \multirow[b]{2}{*}{ SE } & \multicolumn{2}{|c|}{$\begin{array}{c}\text { Bias-Corrected } \\
\text { 95\% CI }\end{array}$} \\
\hline & & & Lower & Upper \\
\hline Low team ID $(4.23 ;-1 \mathrm{SD})$ & $.34^{\star * *}$ & .10 & .15 & .54 \\
\hline Mean (5.22) & $.19^{*}$ & .08 & .04 & .35 \\
\hline High team ID $(6.20 ;+1$ SD $)$ & .04 & .12 & -.20 & .28 \\
\hline 10th percentile of team ID & $.37^{\star \star \star}$ & .11 & .15 & .58 \\
\hline 25 th percentile of team ID & $.31^{\star * *}$ & .09 & .13 & .49 \\
\hline 50 th percentile of team ID & $.21^{\star \star}$ & .08 & .06 & .36 \\
\hline 75th percentile of team ID & .11 & .10 & -.09 & .30 \\
\hline 90th percentile of team ID & .01 & .13 & -.27 & .27 \\
\hline \multirow{2}{*}{$\begin{array}{c}\text { Team ID between } \\
\text { Rumination and Revisit } \\
\text { Intention }\end{array}$} & \multirow[b]{2}{*}{ B } & \multirow[b]{2}{*}{ SE } & \multicolumn{2}{|c|}{$\begin{array}{c}\text { Bias-Corrected } \\
95 \% \mathrm{CI}\end{array}$} \\
\hline & & & Lower & Upper \\
\hline Low team ID $(4.23 ;-1 \mathrm{SD})$ & $.48^{\star * *}$ & .12 & .24 & .71 \\
\hline Mean (5.22) & $.20^{\star *}$ & .08 & .05 & .36 \\
\hline High team ID $(6.20 ;+1 \mathrm{SD})$ & -.07 & .10 & -.28 & .14 \\
\hline 10th percentile of team ID & $.54^{\star * \star}$ & .13 & .28 & .80 \\
\hline 25 th percentile of team ID & $.36^{* * *}$ & .09 & .17 & .54 \\
\hline 50th percentile of team ID & $.17^{\star}$ & .08 & .02 & .32 \\
\hline 75th percentile of team ID & -.02 & .09 & -.20 & .17 \\
\hline 90th percentile of team ID & -.11 & .11 & -.33 & .11 \\
\hline
\end{tabular}

a simple slope ( $\pm 1 S D$ of the mean of team ID) and percentiles of team ID (10th, 25th, 50th, 75th, and 90th). As indicated in Table 5, the magnitudes of the unstandardized coefficients between anger and revisit intention and between rumination and revisit intention were stronger in the low and mean levels of the team ID group (i.e., -1 SD, mean, 10th, 25th, and 50th), and the values were significant. On the other hand, there were no significant effects of anger and rumination on revisit intention in the high levels of team ID groups (i.e., $+1 S D, 75$ th, and 90 th). The results indicated that spectators whose team ID levels were above mean were not affected by anger and rumination in attending a future game.

Discussion. Through Study 2, we demonstrated that ruminating about a previous SDB incident can evoke anger and reduce revisit intention. Elicited anger can also negatively affect revisit intention. The findings indicate that SDB might have negative lingering effects on spectators' anger and revisit intention even after games. We also found that the negative effects of rumination and anger on revisit intention can be buffered by a high level of team ID. That is, unlike the low-level team ID group, highly identified spectators are capable of overcoming prolonged memories of SDB incidents and feelings of anger when deciding to revisit games.

\section{General Discussion}

\section{Summary}

Unlike a majority of previous sport management studies that have focused on positive consumer behavioral factors (e.g., Inoue et al., 2017; Jones et al., 2019), the current study, to the best of our knowledge, is one of the first attempts to explore the negative side of spectator behavior and its impacts on focal spectators' anger, rumination, and revisit intention. To develop survey experimental scenarios in the current research context (i.e., NFL), multiple pretests were conducted in which the SDB incident was identified and survey experimental stimuli were created. In addition, we confirmed that anger was the appropriate negative emotion in the SDB situation. With the developed scenarios, in Study 1, we found that SDB (vs. SNB) decreased revisit intention because it evoked anger. High team ID positively moderated the negative relationships between SDB and revisit intention, and between anger and revisit intention. The results of Study 2 showed that ruminative episodes on SDB incidents negatively predicted revisit intention via elicited anger. It was also found that the negative effects of rumination and anger on revisit intention were more greatly reduced in a high-level team ID group than in a low-level team ID group. In the following sections, we discuss the theoretical contributions and practical implications.

\section{Theoretical contributions}

Sport Management Literature. The current study contributes to the sport management literature by touching on the area of SDB, which has previously received little attention despite its prevalence in reality. As spectators do not always engage in desirable behavior (e.g., cheering, helping others) during live sporting events, highlighting undesirable spectator behavior (i.e., SDB) might provide a novel theoretical understanding of sport spectator behavior. Although efforts have been made to examine the significance of SDB on sport consumer behavior (e.g., Wann \& Goeke, 2018; Wann \& Ostrander, 2017; Wann et al., 2017), these studies are limited to reporting the positive link between team ID and SDB and have not fully captured the consequences of SDB on focal spectators' emotional, cognitive, and behavioral reactions. The present study incorporated anger, rumination, team ID, and revisit intention for the clear understanding of the dark side of spectator behavior. We hope that the current research serves to illuminate a variety of interesting future research agendas. 
The Expectancy Violations Theory and Emotions. The present research extends the expectancy violations theory (Burgoon \& Hale, 1988) by bringing its concept into spectator sport. Our results that SDB increased focal spectators' anger and deceased revisit intention (Study 1) are supported by the expectancy violations theory (Burgoon \& Hale, 1988), which notes that the acts of SDB exceed what are considered to be generally accepted norms and thus cause a negative violation, resulting in unfavorable outcomes of social interactions (Burgoon \& Hale, 1988). The findings also add to the existing SDB literature by demonstrating that innocent bystanders can have angry feelings due to SDB incidents and may then be unwilling to return to the stadium for another game. Consistent with previous research regarding anger (e.g., Bonifield \& Cole, 2007; Grégoire \& Fisher, 2008), we found that angry spectators negatively reported their revisit intention.

Furthermore, by attending to arguments that negative emotions are distinctively elicited by specific contexts (Manstead \& Fischer, 2001), we sought to specify the negative emotion of anger in the context of SDB based on the literature review and empirical test. The findings supported the differential effects of negative emotions such that anger, more so than other negative emotions (e.g., worry, sadness), was elicited in response to SDB. This suggests that though highly correlated, negative emotions may not always be evoked to the same degree. Therefore, a categorical approach to emotions (i.e., positive vs. negative) should be employed with caution as it might overshadow distinct features of specific emotional responses to unique consumption circumstances.

Rumination. Although it is well documented that ruminative thoughts on transgressions can cause the maintenance of negative emotions and lingering impacts on individuals, rumination has been scarcely integrated into the domain of consumer behavior (Strizhakova et al., 2012; Wang et al., 2013), particularly sport consumer behavior research. In the context of SDB, previous researchers have overlooked the notion that witnessing SDB might go beyond the immediate consumption episode by prolonging spectators' memories later. In application of the concept of rumination, we extend previous studies by testing and confirming the proposition that the negative experiences of witnessing SDB incidents persisted after games, which in turn triggered angry feelings and minimized revisit intention. This empirical evidence adds to the sport transgression literature (e.g., Chien et al., 2016) by showing that transgressions committed by spectators, athletes, or teams may not only have immediate negative impacts on spectators but may also be stored in spectators' minds in a repetitive manner, which can affect their emotional states and later decision-making processes.

Team Identification. The present study contributes to the literature on team ID. Team ID has generally been treated as a predictor of SDB in previous studies (e.g., Wann \& Goeke, 2018; Wann \& Ostrander, 2017; Wann et al., 2017), but its potential role as a moderator that can mitigate the negative effect of SDB on focal spectators' emotions and revisit intention has been unexplored. Based on the identity theory (Burke, 1991) and the review of the literature, we found that strong team ID played a critical role in predicting spectators' revisit intention regardless of having witnessed SDB, ruminating $\mathrm{SDB}$, and feeling angry. It is well recognized that team identification is a strong determinant of revisit intention, and thus highly identified spectators can overcome poor service, performance, and scandals in attending future games (Chien et al., 2016; Yim \& Byon, 2018). The current study further documents that highly identified spectators are less influenced by SDB, angry feelings, and rumination with regard to their likelihood to attend future games.

Managerial Implications. In light of the alarming rate of SDB, the NFL has made concerted efforts to lessen SDB in and outside of stadiums, such as banning previously ejected spectators from attending games in other cities, considering restricting alcohol sales after the third quarter, utilizing advanced technology in monitoring SDB (e.g., surveillance cameras), operating a texting system to report SDB, and physically deploying security guards (Milligen, 2015). Implementation of a Fan Code of Conduct and a zero-tolerance policy for SDB have led to a substantial rise in arrests of dysfunctional spectators over the last decade (Babb \& Rich, 2016). Despite such laudable efforts, the occurrence of SDB during NFL games is not so easily stopped. In the deep-rooted culture where the beauty of violence of the sport is glorified, belligerent atmospheres in stadiums heighten emotions and beget violence. The consistent eruptions of SDB incidents can be attributed not only to political, economic, and environmental issues across the league but also to American society at large. To this end, all spectators entering NFL stadiums should recognize the responsibilities they have toward other spectators, the sport, and, most of all, themselves.

The empirical findings from the present study suggest that practitioners recognize the adverse effects of SDB on other spectators' emotional and behavioral reactions. Furthermore, the current study showed that highly identified spectators were less influenced by SDB incidents, rumination, and angry feelings than low-level team ID spectators in deciding to attend 
future games. It should be noted that these findings are not indicative of NFL organizations taking advantage of highly identified spectators but continuing their endeavors to build loyal fan bases. Witnessing SDB might not only cause spectators to feel angry; it might also stop them from returning to a stadium, which can negatively affect the establishment or maintenance of fan bases. The following quote was provided by one of the participants in Study 2.

"I remember watching an Eagles game in Philly and I saw a fan on the losing team punched a guy for the comments he made about the loss. Everybody around them started getting involved shouting and fighting. Security had to get involved and escorted them away. I have decided never go back to this stadium [emphasis added]." (female, 34 years old) To minimize the impacts of SDB on witnesses, NFL managers might consider implementing a seat-change policy wherein spectators can seek different seats if they suffer from SDB. As the cause of the physical assault in the opening example originated from one fan standing in front of another and thus blocking his view, enabling spectators to request a change of seat or ticket refund might help prevent SDB incidents. In addition, this policy could serve to preclude situations where focal spectators are seated around unruly and aggressive spectators who have the potential to ruin others' game experiences.

Managers in NFL organizations are already well aware of how to respond to SDB. Having concluded SDB incidents (e.g., calming, conflict resolution, or ejection), they should also be cognizant of how to assuage other spectators' negative emotions and unsafe feelings. This is important not just for short-term (i.e., during a game) but also long-term (i.e., rumination) repercussions. That is, blocking ruminative thoughts regarding SDB is one of the proactive steps toward preventing lasting negative effects on emotions and behavioral intention (Wang et al., 2013). Therefore, practitioners might consider having security guards remain close to the place of an incident for a while to ensure a feeling of safety for witnesses. Furthermore, managers should make the most of online channels wherein spectators who have bad experiences of SDB during a game can express their accounts. In this case, spectators' expressions regarding SDB incidents might reduce further ruminative thoughts, which can consequently have a positive effect on behavioral intention (Strizhakova et al., 2012).

\section{Limitations and Suggestions for Future Research}

Limitations of the current study should be acknowledged and require further investigation. First, through multiple pretests, we conceptualized SDB as physical fighting in Study 1. However, there exists different forms and severity of SDB (Wann \& James, 2019), which might produce varying impacts on emotions, rumination, and revisit intention. Thus, future scholars may extend the present study by identifying and testing other types and severity of SDB. Second, we investigated SDB under the condition of watching a game. However, a significant proportion of SDB occurs outside of the on-field situation, such as on concourses or in restrooms and parking lots (e.g., tailgating) (Spaaij, 2014; Wann \& James, 2019). Therefore, future research might examine whether spectators' witnessing SDB away from the actual game setting affects individuals' emotions, consumption experiences, and ruminative thoughts after the game.

Third, we found that highly identified spectators were more tolerant of SDB in terms of rumination and feelings of anger, making them more likely to attend future games. As Spaaij (2014) reported that SDB may be tolerated and legitimized within an in-group, it would be interesting to see whether spectators justify or even support SDB when the transgressors are within their in-group. Fourth, in the recall process of an SDB incident in Study 2, the specific time of the incident, the severity of the incident, and the types of the incident were not controlled for. According to Kasch, Klein, and Lara (2001), the effects of rumination might fade away over time, and different incidents recalled (e.g., the severity, types) might potentially result in different rumination effects. Therefore, future studies should control for such variables. For instance, a repeated-measures experimental design, where participants are exposed to the same SDB stimuli at a time and then are asked to report their rumination at a later time, could be considered.

Furthermore, the construct of rumination can be extended to various research contexts, particularly undesirable situations. For example, as noted earlier, future research might examine how spectators' rumination about athletes' or sport teams' transgressions influence their emotional, attitudinal, and behavioral reactions. Another research area is examining the effects of rumination about spectators' favorite team's loss, or the loss of a rivalry game, on their well-being. As sport spectatorship has been known to positively influence spectators' life satisfaction (Inoue et al., 2017), it would be interesting to investigate how rumination on a negative game outcome affects spectators' daily lives.

Finally, in addition to team ID, factors that can mitigate the negative effects of SDB on emotions and revisit intention should be further identified. For instance, individuals adopt coping strategies when managing and 
regulating their negative emotions elicited by undesirable encounters-either by suppressing or expressing them (Lazarus, 1991). Strizhakova et al. (2012) reported that individuals with an expressive (i.e., expressing emotions) coping style ruminated less on bad incidents than those who attempted to actively address problems (i.e., active coping). Likewise, understanding spectators' coping mechanisms in response to SDB can offer theoretical explanations regarding how spectators deal with SDB and engage in revisit intention.

\section{Reference}

Babb, K., \& Rich, S. (2016). A quietly escalating issue for NFL: Fan violence and how to contain it. The Washington Post. https://www.washingtonpost.com/sports/redskins/a-quietlyescalating-issue-for-nfl-fan-violence-and-how-to-containit/2016/10/28/4ec37964-9470-11e6-bb29-bf2701dbe0a3_story. html?utm_term $=.1$ ec $8 \mathrm{f} 6 \mathrm{c} 47871$

Bachman, G. F., \& Guerrero, L. K. (2006). Relational quality and communicative responses following hurtful events in dating relationships: An expectancy violations analysis. Journal of Social and Personal Relationships, 23, 943-963.

Baranik, L. E., Wang, M., Gong, Y., \& Shi, J. (2017). Customer mistreatment, employee health, and job performance: Cognitive rumination and social sharing as mediating mechanisms. Journal of Management, 43, 1261-1282.

BBC Sport (2018). Football-related arrests lowest in a decade \& Birmingham City top arrest list. https://www.bbc.com/sport/ football $/ 46220337$

Bonifield, C., \& Cole, C. (2007). Affective responses to service failure: Anger, regret, and retaliatory versus conciliatory responses. Marketing Letters, 18, 85-99.

Brocato, E. D., Voorhees, C. M., \& Baker, J. (2012). Understanding the influence of cues from other customers in the service experience: A scale development and validation. Journal of Retailing, 88, 384-398.

Burgoon, J. K., \& Hale, J. L. (1988). Nonverbal expectancy violations: Model elaboration and application to immediacy behaviors. Communications Monographs, 55, 58-79.

Burke, P. J. (1991). Identity processes and social stress. American Sociological Review, 56, 836-849.

Chien, P. M., Kelly, S. J., \& Weeks, C. S. (2016). Sport scandal and sponsorship decisions: Team identification matters. Journal of Sport Management, 30, 490-505.

Fornell, C., \& Larcker, D. (1981). Evaluating structural equation models with unobservable variables and measurement error. Journal of Marketing Research, 18, 39-50.

Fullerton, R. A., \& Punj, G. (2004). Repercussions of promoting an ideology of consumption: Consumer misbehavior. Journal of Business Research, 57, 1239-1249.

Grégoire, Y., \& Fisher, R. J. (2008). Customer betrayal and retaliation: When your best customers become your worst enemies. Journal of the Academy of Marketing Science, 36, 247-261.

Hayes, A. F. (2013). Introduction to mediation, moderation, and conditional process analysis: A regression-based approach. Guilford Pass.

Hoyle, R. H., \& Panter, A. T. (1995). Writing about structural equation models. In R. H. Hoyle (Ed.), Structural equation modeling: Concepts, issues, and applications (pp. 158-176). Sage.

Hunt, K. A., Bristol, T., \& Bashaw, R. E. (1999). A conceptual approach to classifying sports fans. Journal of Services Marketing, 13, 439-452.
Inoue, Y., Sato, M., Filo, K., Du, J., \& Funk, D. C. (2017). Sport spectatorship and life satisfaction: A multicountry investigation. Journal of Sport Management, 31, 419-432.

Jacobson, B. (2003). The social psychology of the creation of a sports fan identity: A theoretical review of the literature. Athletic Insight: The Online Journal of Sport Psychology, 5, 1-14.

Jones, C. W., Byon, K. K., \& Huang, H. R. (2019). Service quality, perceived value, and fan engagement: Case of Shanghai Formula One racing. Sport Marketing Quarterly, 28(2), 63-76.

Kalamas, M., Laroche, M., \& Makdessian, L. (2008). Reaching the boiling point: Spectators' negative affective reactions to firm-attributed service failures. Journal of Business Research, 61, 813-824.

Kasch, K. L., Klein, D. N., \& Lara, M. E. (2001). A construct validation study of the response styles questionnaire rumination scale in participants with a recent-onset major depressive episode. Psychological Assessment, 13, 375-383.

Kim, K. A., Byon, K. K., \& Baek, W. Y. (2019). Customer-to-customer value co-creation and co-destruction in sporting events. The Service Industries Journal, 40(9-10), 633-655.

Kim, K. A., Byon, K. K., Baek, W. Y., \& Williams, A. (2019). Examining structural relationships among sport service environments, excitement, consumer-to-consumer interaction, and consumer citizenship behaviors. International Journal of Hospitality Management, 82, 318-325.

Lazarus, R. S. (1991). Progress on a cognitive-motivational-relational theory of emotion. American Psychologist, 46, 819-834.

Lock, D., \& Heere, B. (2017). Identity crisis: A theoretical analysis of 'team identification' research. European Sport Management Quarterly, 17, 413-435.

Manstead, A. S., \& Fischer, A. H. (2001). Social appraisal: The social world as object of and influence of appraisal processes. In K. R. Scherer, A, Schorr, \& T. Johnstone (Eds.), Appraisal processes in emotion: Theory, methods, research (pp. 221-232). Oxford University Press.

McCullough, M. E., Bono, G., \& Root, L. M. (2007). Rumination, emotion, and forgiveness: Three longitudinal studies. Journal of Personality and Social Psychology, 92, 490-505.

Miao, L., Mattila, A. S., \& Mount, D. (2011). Other consumers in service encounters: A script theoretical perspective. International Journal of Hospitality Management, 30, 933-941.

Milligen, D. V. (2015). How to prevent fan violence at sporting events. Athletic Business. https://www.athleticbusiness.com/ stadium-arena-security/how-to-prevent-fan-violence-at-sporting-events.html

Nolen-Hoeksema, S. (1991). Responses to depression and their effects on the duration of depressive episodes. Journal of Abnormal Psychology, 100, 569-582.

Porath, C., MacInnis, D., \& Folkes, V. (2010). Witnessing incivility among employees: Effects on consumer anger and negative inferences about companies. Journal of Consumer Research, 37, 292-303.

Richins, M. L. (1997). Measuring emotions in the consumption experience. Journal of Consumer Research, 24, 127-146.

Rusting, C. L., \& Nolen-Hoeksema, S. (1998). Regulating responses to anger: Effects of rumination and distraction on angry mood. Journal of Personality and Social Psychology, 74, 790-803.

Skinner, E. A., Edge, K., Altman, J., \& Sherwood, H. (2003). Searching for the structure of coping: A review and critique of category systems for classifying ways of coping. Psychological Bulletin, 129, 216-269.

Song, H., You, G. J., Reisinger, Y., Lee, C. K., \& Lee, S. K. (2014). Behavioral intention of visitors to an Oriental medicine festival: An extended model of goal directed behavior. Tourism Management, 42, 101-113. 
Spaaij, R. (2014). Sports crowd violence: An interdisciplinary synthesis. Aggression and Violent Behavior, 19, 146-155.

Strizhakova, Y., Tsarenko, Y., \& Ruth, J. A. (2012). “I'm mad and I can't get that service failure off my mind": Coping and rumination as mediators of anger effects on customer intentions. Journal of Service Research, 15, 414-429.

Tajfel, H. (1981). Human groups and social categories: Studies in social psychology. Cambridge University Press.

Trail, G. T., \& James, J. D. (2001). The motivation scale for sport consumption: Assessment of the scale's psychometric properties. Journal of Sport Behavior, 24, 108-127.

Trail, G. T., Anderson, D. F., \& Lee, D. (2017). A longitudinal study of team-fan role identity on self-reported attendance behavior and future intentions. Journal of Amateur Sport, 3, 27-49.

Wakefield, K. L., \& Sloan, H. J. (1995). The effects of team loyalty and selected stadium factors on spectator attendance. Journal of Sport Management, 9, 153-172.

Wakefield, K. L., \& Wann, D. L. (2006). An examination of dysfunctional sport fans: Method of classification and relationships with problem behaviors. Journal of Leisure Research, 38, 168-186.

Wang, M., Liu, S., Liao, H., Gong, Y., Kammeyer-Mueller, J., \& Shi, J. (2013). Can't get it out of my mind: Employee rumination after customer mistreatment and negative mood in the next morning. Journal of Applied Psychology, 98, 989-1004.

Wann, D. L., \& Goeke, M. E. (2018). Sport fan superstition: The importance of team identification, sport fandom, and fan dysfunction. Journal of Sport Behavior, 41, 227-244.

Wann, D. L., \& James, J. D. (2019). Sport fans: The psychology and social impact of fandom (2nd ed.). Routledge.

Wann, D. L., \& Ostrander, A. (2017). The relationship between dysfunctional sport fandom and assertiveness. Journal of Contemporary Athletics, 11, 189-197.

Wann, D. L., Waddill, P. J., Bono, D., Scheuchner, H., \& Ruga, K. (2017). Sport spectator verbal aggression: The impact of team identification and fan dysfunction on fans' abuse of opponents and officials. Journal of Sport Behavior, 40, 423-443.

Wann, D. L., Weaver, S., Belva, B., Ladd, S., \& Armstrong, S. (2015). Investigating the impact of team identification on the willingness to commit verbal and physical aggression by youth baseball spectators. Journal of Amateur Sport, 1, 1-28.

Yim, B, H., \& Byon, K. K. (2018). The influence of emotions on game and service satisfaction and behavioral intention in winning and losing situations: Moderating effect of identification with the team. Sport Marketing Quarterly, 27, 93-106.

\section{Appendix A. Scenarios for Study 1}

Spectator dysfunctional behavior condition: Imagine that you are watching a game featuring your favorite NFL team at a stadium. As you are seated, you notice that a group of spectators sitting next to you get into a fight. It makes you feel unsafe and distracts you from the game for a while. All other aspects of the stadium experience are as expected.

Spectator normal behavior condition: Imagine that you are watching a game featuring your favorite NFL team at a stadium. As you are seated, you notice a group of spectators sitting next to you. They behave the way you expect in a typical NFL spectatorship situation. All other aspects of the stadium experience are as expected.
Appendix B. Items and Factor Loadings for Studies 1 and 2

\begin{tabular}{|c|c|c|}
\hline \multirow[b]{2}{*}{ Constructs/Items } & \multicolumn{2}{|c|}{ Factor Loadings } \\
\hline & Study 1 & Study 2 \\
\hline \multicolumn{3}{|l|}{ Rumination } \\
\hline $\begin{array}{l}\text { I cannot stop thinking about the other } \\
\text { spectators' dysfunctional behavior. }\end{array}$ & - & .81 \\
\hline $\begin{array}{l}\text { Thoughts and feelings about the other } \\
\text { spectators' dysfunctional behavior keep } \\
\text { running through my head. }\end{array}$ & - & .88 \\
\hline $\begin{array}{l}\text { Strong feelings about the other spectators' } \\
\text { dysfunctional behavior keep bubbling } \\
\text { up. }\end{array}$ & - & .88 \\
\hline $\begin{array}{l}\text { Images of the other spectators' } \\
\text { dysfunctional behavior keep coming } \\
\text { back to me. }\end{array}$ & - & .87 \\
\hline $\begin{array}{l}\text { I brood about the other spectators' } \\
\text { dysfunctional behavior. }\end{array}$ & - & .80 \\
\hline $\begin{array}{l}\text { I find it difficult not to think about the } \\
\text { other spectators' dysfunctional behavior. }\end{array}$ & - & .82 \\
\hline $\begin{array}{l}\text { I find myself playing the other spectators' } \\
\text { dysfunctional behavior over and over in } \\
\text { my mind. }\end{array}$ & - & .86 \\
\hline $\begin{array}{l}\text { Even when I am engaged in other tasks, } \\
\text { I think about the other spectators' } \\
\text { dysfunctional behavior. }\end{array}$ & - & .84 \\
\hline \multicolumn{3}{|l|}{ Anger } \\
\hline I feel frustrated. & .88 & .87 \\
\hline I feel angry. & .84 & .85 \\
\hline I feel irritated. & .92 & .68 \\
\hline \multicolumn{3}{|l|}{ Revisit intention } \\
\hline $\begin{array}{l}\text { I will make an effort to revisit the NFL } \\
\text { game. }\end{array}$ & .83 & .93 \\
\hline I intend to revisit the NFL game. & .95 & .94 \\
\hline I am willing to revisit the NFL game. & .88 & .91 \\
\hline $\begin{array}{l}\text { I intend to save time and money to revisit } \\
\text { the NFL game. }\end{array}$ & .80 & .91 \\
\hline \multicolumn{3}{|l|}{ Team identification } \\
\hline \multicolumn{3}{|l|}{ Study 1} \\
\hline $\begin{array}{l}\text { I consider myself to be a real fan of my } \\
\text { favorite NFL team. }\end{array}$ & .68 & - \\
\hline $\begin{array}{l}\text { I would experience a loss if I had to stop } \\
\text { being a fan of my favorite NFL team. }\end{array}$ & .86 & - \\
\hline $\begin{array}{l}\text { Being a fan of my favorite NFL team is } \\
\text { very important to me. }\end{array}$ & .82 & - \\
\hline \multicolumn{3}{|l|}{ Study 2} \\
\hline $\begin{array}{l}\text { I consider myself to be a real fan of the } \\
\text { NFL team I recalled. }\end{array}$ & - & .55 \\
\hline $\begin{array}{l}\text { I would experience a loss if I had to stop } \\
\text { being a fan of the NFL team I recalled. }\end{array}$ & - & .74 \\
\hline $\begin{array}{l}\text { Being a fan of the NFL team I recalled is } \\
\text { very important to me. }\end{array}$ & - & .87 \\
\hline
\end{tabular}


Copyright of Sport Marketing Quarterly is the property of Fitness Information Technology, Inc. and its content may not be copied or emailed to multiple sites or posted to a listserv without the copyright holder's express written permission. However, users may print, download, or email articles for individual use. 